\title{
Implications of Unprofitable Horizontal Mergers: A Positive External Effect Does Not Suffice To Clear A Merger!
}

\author{
Oliver Budzinski' ${ }^{1}$ Jürgen-Peter Kretschmer ${ }^{2}$
}

\begin{abstract}
Standard analysis of mergers in oligopolies along the lines of the popular Farrell-Shapiro Framework (FSF) relies, regarding its policy conclusions, on the assumption that rational agents will only propose privately profitable mergers. If this assumption were held, a positive external effect of a proposed merger would represent a sufficient condition to allow the merger. However, the empirical picture on mergers and acquisitions reveals a significant share of unprofitable mergers, and economic theory, moreover, demonstrates that privately unprofitable mergers can be the result of rational action. Therefore, we drop this restrictive assumption and allow for unprofitable mergers to occur. This exerts a considerable impact on merger policy conclusions: while several insights of the original analysis are corroborated (e.g., efficiency defense), a positive external effect does not represent a sufficient condition for the allowance of a merger any longer. Applying such a rule would cause a considerable amount of false decisions.
\end{abstract}

KEY WORDS: $\quad$ mergers \& acquisitions, oligopoly theory, horizontal merger policy, profitability of mergers, antitrust

JEL Classification: L13, L41, K21, D43

${ }^{1}$ IImenau University of Technology, Institute of Economics, Germany; ${ }^{2}$ Federal Cartel Office, Germany

\section{Introduction}

The framework for analyzing horizontal mergers introduced by Farrell and Shapiro (1990) has become very popular in industrial and business economics. In the context of the so-called 'more-economic approach to competition policy' (Neven, 2006), this framework additionally enjoys an increasing importance for empirical and policy analyses of horizontal mergers and,

Correspondenceconcerning this articleshould beaddressed to: Oliver Budzinski, IImenau University of Technology, Institute of Economics, Ehrenbergstraße 29, D-98693 IImenau, Germany. T: +49 367769 4030, F: +49 367769 4203. E-mail: oliver.budzinski@tu-ilmenau.de consequently, also for the self-assessment of business companies considering a merger project. One of the most distinctive characteristics of the Farrell-Shapiro framework (FSF) is the conceptual differentiation between an 'internal effect' (on the merging companies) and an 'external effect' (on the competitors of the merging companies and on the consumers). This allows for a clarified interpretation of an 'efficiency defense': the total welfare of a horizontal merger is positive if the positive internal effect overcompensates for a negative external effect. Furthermore, any horizontal merger entailing a positive external effect is deemed to be welfare enhancing (Farrell \& Shapiro 1990; 1991). This policy conclusion is rooted in a crucial assump- 
tion: because rational enterprises will only engage in a merger if the combination increases the profitability of the merged entity compared to the non-merged companies, Farrell and Shapiro $(1990 ; 1991)$ assume that only profitable mergers will occur (the increase in profits might either be a result of efficiencies, for instance, synergy effects or economies of scale, or a result of market power), i.e., the internal effect of rational mergers is always positive. In doing so, they find themselves in line with the majority of industrial economics analyses of horizontal mergers.

Although the limitation to profitable mergers on the grounds of the rationality assumption appears to be straightforward, the empirical picture differs significantly. According to the vast majority of empirical studies on merger profitability, a considerable share of horizontal mergers fails to enhance profitability ex post (section 2). Moreover, it can be argued that unprofitable mergers might well be undertaken by rational agents (section 2). Therefore, we re-configure the FSF by introducing the possibility of unprofitable mergers occurring (section 3). Against this background, we review the policy conclusions given by Farrell and Shapiro (section 4). While we support some of their recommendations, we also find cases in which the disregard of unprofitable mergers impedes a welfare-maximizing merger policy.

\section{2. (Un-)Profitability of Mergers}

The comprehensive empirical literature on the profitability of mergers is typically classified into two methodological approaches: first, the 'success' of a merger is evaluated against the background of data from balance sheets pre- and post-merger, so-called outcome studies. These studies generally identify a significant share of mergers that decrease profits as well as profitability post-merger. Depending on the analyzed timeframe and the included industries, the ratio of unprofitable mergers lies between 25 and 50 percent (Gugler et al., 2003; Kaplan \& Weisbach, 1992; Pautler 2003; Ravenscraft \& Scherer, 1987; Röller, Stennek, \& Verboven, 2006; Tichy, 2001). This share tends to increase with the transaction volume of the merger. Gugler et al. (2003) find that only approximately 30 percent succeeded in improving both profits and sales compared to a control group of non-merging companies. Furthermore, indication exists that internal growth performs systematically better than external growth through M\&A activity (Dickerson, Gibson, \& Tsakalotos, 1997). Second, so-called event studies analyze stock market reactions to merger announcements. The underlying idea is that capital markets reflect the profitability changes in the course of mergers and acquisitions through the evolution of (abnormal) stock returns. While studies that restrict themselves to a short window of time around the announcement generally find a large share of value-increasing mergers, those that employ a longer window of time - in particular, extending to several years post-merger show a wide distribution of results with a generally negative mean tendency (Andrade, Mitchell, \& Stafford, 2001; Pautler, 2003; Rau \& Vermaelen, 1998; Röller et al., 2006; Tichy, 2001).

Each of these studies may be criticized on methodological grounds (e.g., Beigi \& Budzinski 2013), and their results are far from being homogeneous or mutually congruent. However, irrespective of the diversity of methods and irrespective of the respectively derived share of unprofitable mergers, the empirical picture clearly shows that unprofitable mergers do occur and do not represent a rare or negligible exception. This alone justifies including the possibility of unprofitable mergers in policy-relevant modeling. Does it, however, really contradict the model assumptions? In the FSF, it is assumed that rational enterprises engage only in profitable mergers. In principle, this offers scope for irrational (unprofitable) mergers. However, it seems a priori dissatisfying to label all unprofitable mergers 'irrational'. Therefore, the question arises whether rational agents might engage in unprofitable mergers. Therefore, why do unprofitable mergers occur?

First, principal-agent problems between owners and managers can promote unprofitable mergers (Firth, 1980; Jensen, 1986). Rational managers will maximize their individual utility. Elements of the respective utility functions might include income, power, prestige, publicity or career opportunities - factors that depend more upon the size and growth of the company than on profitability (Jensen, 1986; Tichy, 2001). The literature refers to concepts like empire building (Shleifer \& Vishny, 1988; Trautwein, 1990), hubris (Roll, 1986), or free cash (Jensen, 1986; Bruner, 1988). Second, consultants may also be self-interested and, therefore, pro- 
mote unprofitable mergers because creating a merger can be more profitable for consultants than preventing a merger. Moreover, post-merger re-organization represents a lucrative follow-up business. Obviously, rational consultants will not promote unprofitable mergers if they can be made responsible for this ex post (negative reputation effects). However, in combination with imperfect ex ante information, it may be difficult and ambiguous to identify the reasons of failure in ex post evaluation. Why, for instance, did the Daimler-Chrysler merger fail? Was it wrong from the beginning or due to bad policy post-merger or even external, unpredictable market circumstances (e.g., the unexpected decline of the SUV-segment in the U.S.)? Thus, rational consultants might expect to escape without reputation damage, in particular if the assessment is a close call (i.e., a merger project is on the brink of profitability). An unambiguously unprofitable merger, however, can hardly be explained along these lines. In these two cases, resulting mergers might not be rational from an enterprise point of view, but they are, nevertheless, the result of individually rational agents acting within organizations (with normal control problems). Consequently, ex ante unprofitable merger projects are conducted as a result of rational individual action.

Third, preemptive and defensive mergers might occur (Fridolfsson \& Stennek, 2005). Company A might decide to merge with company $B$ despite a lack of profitability of this combination to prevent B from merging with $C$ (building of a powerful competitor) - an alternative that would be even worse for company A. Similarly, a merger might be done to prevent a hostile takeover of any merging party by $\mathrm{C}$ (white knight mergers). Although unprofitable in absolute terms, preemptive and defensive mergers might represent the less unprofitable choice for a specific enterprise. Thus, an unprofitable merger is rationally undertaken.

Fourth, mergers and especially merger waves are explained with psychological phenomena, such as herd behavior (merging because everyone else merges), information cascades, and framing effects, etc. It is debatable whether such phenomena belong to rational behavior. While advanced concepts of rationality - referring to human cognitive and mental processes and their limits - would include them (Budzinski, 2003; Kahneman, 2003a; 2003b), these modes of be- havior might well fall outside more traditional concepts of rationality.

In summary, empirical evidence shows that unprofitable mergers occur with considerable frequency, and theoretical explanations note that rational agents have incentives to engage in unprofitable mergers. Therefore, merger policy cannot rely on a positive internal effect, i.e., that any proposed merger increases the profits of the merged entity compared to the single enterprises, either through (procompetitive) efficiency gains or through (anticompetitive) exploitation of market power. Sound merger policy decisions thus require consideration of the frequent occurrence of unprofitable mergers with a negative internal effect. To demonstrate the implications of this, we now address the FSF in more detail.

\section{Unprofitable Mergers in the Farrell-Shapiro Framework}

\subsection{The Farrell-Shapiro Framework}

Farrell and Shapiro (1990) use a model of Cournot oligopoly with homogenous goods. Inverse demand is given by $p(X)$, where $X$ is the total industry output, $p$ is the price, and $p^{\prime}(X)<0$. The number of firms is exogenous and given by $n$, which rules out the entry of new firms. Farrell and Shapiro (1990) consider only the entry of new firms that behave oligopolistically. The entry by and existence of price-taking fringe firms is, however, not ruled out by the model framework. In this case, $p(X)$ can be interpreted as the residual demand curve facing the oligopolists.

Firm $i$ 's output and cost functions are given by $x_{i}$ and $c^{i}\left(x_{i}\right)$, respectively, and $c_{x}^{i}\left(x_{i}\right)$ denotes firm $i$ 's marginal cost. Total industry output is therefore given by $X=\sum_{i=1}^{n} x_{i}$, and $y_{i}=\sum_{j \neq i} x_{j}=X-x_{i}$ summarizes the aggregated output of all firms other than firm $i$.

In the Cournot equilibrium, every firm $i$ maximizes its profits, $\pi^{i}\left(x_{i}, y_{i}\right)=p\left(x_{i}+y_{i}\right) x_{i}-c^{i}\left(x_{i}\right)$, over its output $x_{i}$, given its rivals' output $y_{i}$. The solution is an output vector $\left(x_{1}, \ldots, x_{n}\right)$, such that the first-order condition,

$\frac{\partial \pi^{i}}{\partial x_{i}}=p(X)+x_{i} p^{\prime}(X)-c_{x}^{i}\left(x_{i}\right)=0, \quad i=1, \ldots, n$,

holds for all $n$ firms, whereas the existence and stability of a Cournot equilibrium requires the fulfillment of two weak assumptions on a given range: 
(a) Each firm's reaction curve - which is given by (1) slopes downward. This is equivalent with the requirement that firm i's marginal revenue is lowered by an increase in rivals' output (Novshek, 1985), i.e.

$p^{\prime}\left(x_{i}+y_{i}\right)+x_{i} p^{\prime \prime}\left(x_{i}+y_{i}\right)<0$.

(b) Firm is residual demand curve intersects its marginal cost curve from above. Equivalently,

$c_{x x}^{i}\left(x_{i}\right)>p^{\prime}(X)$.

The slope of firm is reaction schedule can be derived from equation (1): $\frac{d x_{i}}{d y_{i}}=R_{i}$, where $-1<R_{i}<0$ because of (2) and (3). This means that firm $i$ reduces its output if the other firms jointly expand their production. However, firm $i$ contracts its output by less. Converting the slope of the reaction curve gives:

$d x_{i}=-\lambda_{i} d X$,

where $\lambda_{i}=-\frac{R_{i}}{1+R_{i}}>0$ under the conditions given by (2) and (3), which measures firm is "output response to changes in industry output" (Werden, 1991).

This results in the effect of an exogenous output change of firm 1 on the total industry output, which is given by the "Lemma" (Farrell \& Shapiro, 1990) Consider an exogenous change in firm 1's output, and let the other firms' output adjust to re-establish a Cournot equilibrium among themselves. If firms' reaction curves slope downward (condition [2]), and if the stability condition [3] holds, then aggregate output moves in the same direction as firm 1's output, but by less. That is: $1>\frac{d X}{d x_{1}}>0$.

To analyze the effect of a horizontal merger on total output, the cost function of the merged entity $M, c^{M}(\cdot)$, must be compared with the cost functions of the merging firms ("insiders"). The central result is given in proposition 1, whereby " $M$ must enjoy substantially lower marginal costs than did its constituent firms, if price is to fall", and industry output increases, respectively (Farrell \& Shapiro, 1990). The larger the pre-merger market shares of the constituent firms were, the larger must be this cost reduction. It is therefore not unreasonable to expect a reduction in total output as a result of a merger.

The following consideration of the total welfare effects contains the crucial assumption that proposed mergers are privately profitable, i.e., the change in the insiders' $(I)$ total profits is positive $\left(\Delta \pi^{I}>0\right)$. Under this central assumption, a merger will raise welfare if it has a positive external effect on consumers and the nonparticipant firms ("outsiders") jointly (Farrell \& Shapiro, 1990).

The sign of the external effect is determined by considering the reaction of the outsiders $O$ with respect to an output change of the insiders. This allows the determination of the total effect on outsiders' profits $\pi^{\circ}$ and consumer surplus CS. The change in equilibrium output by the insiders, $\Delta X_{I}$, can be treated as exogenous because "consumers care only about the net effect on aggregate output, $\Delta X$, and [...] rivals care only about the change in equilibrium output by the merging ('insider') firms, $\Delta X_{I}$, not about what caused that change" (Farrell \& Shapiro, 1990). The total change in insiders' output $\Delta X_{I}$ is considered as the integral of infinitesimal changes $d X_{I}$. First, the external effect is determined due to an infinitesimal merg$\mathrm{er}$, and the total external effect is the integral of the effects of these infinitesimal mergers. The latter are given by

$$
d W-d \pi^{I}=\underbrace{\left(\sum_{i \in O} \lambda_{i} x_{i}-X_{I}\right)}_{\equiv \eta} \times p^{\prime}(X) d X .
$$

Given the reasons that determine the change in insiders' output, it is particularly important to consider the case of an output reduction. Converting $\eta$ into market

shares, i.e., $s_{i}=\frac{x_{i}}{X}$, the external effect is positive if the

sum of the outsiders' market shares - weighted by their reaction parameters - is larger than the insiders' market shares, i.e., $\sum_{i \in O} \lambda_{i} s_{i}>s_{I}$ (see proposition 4 of Farrell and Shapiro, 1990)

To determine the total external effect, it must be shown that this condition is fulfilled along a "path" given by $\Delta X_{I}$. Hence, "the net externality is a weighted integral of $\eta$ along a path from $X_{I}^{\text {initial }}$ to $X_{I}^{\text {final }}$ " (Farrell \& Shapiro, 1990):

$$
\Delta W-\Delta \pi^{I}=\int_{X_{i}^{\text {final }}}^{X_{\text {intial }}^{\text {ind }}} \eta(X)\left[-p^{\prime}(X)\right] \frac{d X}{d X_{I}} d X_{I} .
$$


The lower and upper bound of the integral are given by $X_{I}^{\text {final }}$ and $X_{I}^{\text {inital }}$, respectively, because the insider output falls from $X_{I}^{\text {initial }}$ to $X_{I}^{\text {final }}$.

In proposition 5 (Farrell \& Shapiro, 1990), sufficient conditions are given for an increase of $\eta$ as $X_{I}$ falls. If these conditions are fulfilled, it follows for $\eta \geq 0$ before a merger that an output reducing and profitable merger results in an increase in total welfare. Therefore, any proposed merger that is aligned with a positive external effect should be allowed. If the external effect of a merger is negative, the reverse does not apply automatically, and the positive change in insiders' profits can offset the negative external effect. These conclusions are based on the presumption that mergers are only proposed if they are privately profitable, i.e., $\Delta \pi^{I}>0$. The case of unprofitable mergers is explicitly ruled out of the analysis (Farrell \& Shapiro, 1990).

\subsection{Extensions and Modifications}

This section gives a brief literature-based overview of models that modify and enhance the FSF. In regards to the aim of this paper, we particularly focus on whether the profitability assumption becomes modified. Barros and Cabral (1994) apply the FSF to mergers in open economies. They uphold the assumption that only profitable mergers are proposed and introduce merger control authorities. If consumers and producers are located in different countries, different objective functions of an international merger authority and national authorities and the resulting welfare implications are analyzed. Levin (1990) analyses the effects of mergers of a fraction of firms in markets where the outsiders are restricted to behaving à la Cournot, whereas the insiders (i.e., merging firms) are not. The results supplement the ones of Farrell and Shapiro (1990). Concerning welfare analysis, the focus lies on profitable mergers. Any proposed merger of a fraction of firms with no more than 50 percent of the premerger market share causes welfare to rise. Additionally, in a Cournot setting, Hennessy (2000) regards mergers of a small fraction of firms. He contrasts the view that these mergers are motivated by cost efficiencies instead of enhancing market power. In doing so, he refers to special industry demand curves that allow the occurrence of welfare-reducing mergers because of their private profitability even without cost efficiencies.

Verboven (1995) compares the results of the static Cournot model of Farrell and Shapiro (1990) with a model of quantity-setting firms that behave collusively. Assuming a linear demand function, the insiders' maximum allowable market share in the case of an output-decreasing capital transfer is higher than with Farrell and Shapiro (1990). However, this comparison also considers only privately profitable mergers. Spector (2003) allows for market entries in the FSF and analyses profitable mergers according to a consumer welfare standard. If mergers fail to generate synergies or economies of scale (not induced by fixed costs), then consumers are harmed, i.e., prices are higher, irrespective of entry conditions. Brueckner and Spiller (1991) consider airline networks (hub-and-spoke networks), which are characterized by economies of density and costs of complementarities. Competition on parts of these networks generates negative externalities on markets outside the competitive parts. As a result, mergers on the competitive parts can have net positive gains in consumer surplus, which leads them to the reconsideration of antitrust policy in not focusing attention on the parts where market power may increase. They do not, however, explicitly consider unprofitable mergers in evaluating the overall welfare effect.

Nilssen and Sørgard (1998) regard sequential merger decisions of disjoint groups of firms and their intertemporal dependence. Most important with respect to our analysis is the strategic motive, which reflects the effect of one merger on possible future merger decisions by rival firms, and its implications for policy conclusions. Concerning unprofitable mergers, the strategic motive explains these in expectation of future mergers, which will have a positive feedback for the first. While the policy conclusions are derived by explicitly referring to and reconsidering the argumentation of the FSF, the analysis of Nilssen and Sørgard (1998) is distinct to ours in that they refer to the possible intertemporal dependences of merger decisions and the effects on the evaluation of welfare effects. Our analysis focuses on the effects of introducing unprofitable mergers and the implications on assessment decisions for these based on the FSF.

Fridolfsson (2007) analyses endogenous merger formation. In this setup, firms have strong incentives to engage in anti- rather than procompetitive mergers. One reason is that firms pre-empt being an outsider of procompetitive mergers, which would have a negative external effect on them. The lack of pursuing procom- 
petitive mergers, which would result in an output-increase, is the benefit (i.e., external effect) that outsiders gain from anticompetitive mergers. As a policy conclusion, Fridolfsson (2007) regards the assessment of the relevant alternatives to a proposed merger, which may be another merger rather than the original market structure. However, this approach focuses on an endogenous explanation of the formation of unprofitable mergers, whereas we analyze the effects of unprofitable mergers (however motivated) in the FSF.

Cheung (1992) addresses the problem of an automatic inference from the proposition of mergers on the creation of a minimal level of required cost savings because of the profitability assumption. Because output-increasing mergers can reduce welfare, Cheung (1992) shows - by means of a simple numerical example - that these mergers have an incentive to underestimate cost savings to imitate output-reducing mergers. The application of Farrell and Shapiro's externality condition does not handle this problem because proposed mergers are assumed to be privately profitable, and the fulfillment of the externality condition indicates a welfare-improving merger. As a result, some welfare-reducing mergers are allowed. He provides his policy conclusions by either obtaining more precise information or by banning all output-reducing mergers. Cheung's numerical example fits as a special case of our more general treatment of the problem.

Two specifically interesting papers address an oftenneglected subcase of the FSF. When mergers are privately not profitable (wherefore they are not done) but desirable from a total welfare perspective, then according to Fauli-Oller (2002) and Dragone, Lambertini and Mantovani(2006) subsidizing the unwilling-to-merge firms becomes the welfare-optimal merger policy in a couple of very specific cases. However, note that both Fauli-Oller (2002) and Dragone et al. (2006) restrict their analyses to very specific cases - declining industries and industries with plenty of competitors plus insignificant fixed costs, respectively. We will address this issue more closely in our more general framework in section 4 .

\subsection{Introducing Unprofitable Mergers}

We now introduce the consideration of unprofitable mergers in the FSF. Derived from the analysis in section 3.1, we consider the case of an output-reducing merger, i.e., $\Delta X_{I}<0$. It emerges from proposition 1 that this case is very reasonable because an increase in output requires substantially lower marginal costs of the merged entity compared to its constituent firms. As Farrell and Shapiro (1990, p. 111) note, "[m]ergers differ enormously in the extent to which productive assets can usefully be recombined". The authors permit possible relationships between the merged entity's cost function and the cost functions of its constituent firms, but they explicitly refer to changes that follow anticompetitive motivations, rationalization or synergies. Wherewith, it is implicitly assumed that the change in costs is positive (because the authors primarily consider output-reducing mergers, it is implicitly assumed that this positive change in costs is not big enough). Because no $a$ priori assumptions on the merged entity's cost function are made - except the ones given by conditions (2) and (3) - negative movements of costs due to a merger are not ruled out.

If the assumption of privately profitable mergers is removed, two important conclusions can be drawn: First, it is permitted that a change in costs due to a merger was misjudged, is unexpected, or was intentional. Hence, we include both the cases of merger projects that appear profitable ex ante but turn out to be unprofitable ex post (failures in post-merger management, imperfect information, etc.) and of such that are already ex ante unprofitable but are conducted due to agency problems or preemptive and defensive strategies (managerial or consultancy interests, preemptive and defensive mergers; see section 2). We treat both cases in the same way because from a competition policy perspective, it is effects that matter and not motives: for merger control, it is only relevant if the effects of a merger lead to a negative internal effect and not whether this was intentional. Second, this need not mean that mergers lead to losses; merely the change in insiders' profits - after the merger combined in the merged entity - is now permitted to be negative. Furthermore, third, this also includes cases of self-interested managers with personal gains from unprofitable mergers (see section 2). While the gains for the managers represent a welfare increase that needs to be deducted from the losses for the shareholders in the case of an unprofitable merger, it appears very unlikely and a far-stretch to assume that these personal gains for a few individuals may outweigh total unprofitabil- 


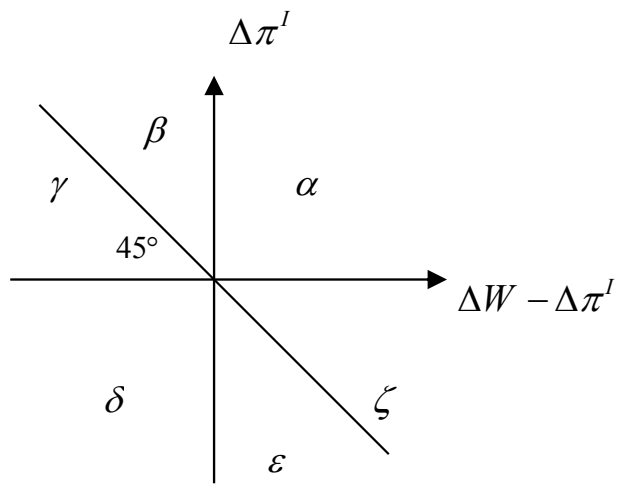

Figure 1. Welfare Effects of Horizontal Mergers (modified version from Farrell and Shapiro's (1990)

ity of a merger. Therefore, we do not explicitly model the manager gains-effect in the following.

Otherwise, the framework of Farrell and Shapiro (1990) is maintained and now used to permit the possibility of unprofitable mergers, i.e., $\Delta \pi^{I}<0$. Given the reasons that determine the change in insiders' output, we focus on output-reducing mergers, i.e., $\Delta X_{I}<0$. This is most plausible if it is assumed that a negative change in insiders' profits is the result of disadvantageous cost changes.

Again, the case of an infinitesimal merger is considered first. The external effect is given by (5). After converting $\eta$ into market shares, i.e., $\sum_{i \in O} \lambda_{i} s_{i}-s_{I}$, the reasoning is thus analogous to the one given in proposition 4. A small reduction in insiders' output has a net negative welfare effect on outsiders and consumers if and only if the sum of the outsiders' market shares weighted by their reaction parameters - is smaller than the insiders' market shares, i.e., $s_{I}>\sum_{i \in O} \lambda_{i} s_{i}$.

To discuss the total external effect, the integral of infinitesimal changes must be considered. As noted above and given by (6), "the net externality is a weighted integral of $\eta$ along a path from $X_{I}^{\text {initial }}$ to $X_{I}^{\text {final }}$ " (Farrell \& Shapiro, 1990). A sufficient condition for the total effect on outsiders and consumers to be negative is fulfilled if $\eta<0$ after the merger (Farrell \& Shapiro, 1990). It is sufficient for an output-reducing merger because $\eta$ increases as $X_{I}$ falls (see proposition 5 in Farrell and Shapiro (1990); the authors give sufficient conditions for an increase of $\eta$ as $X_{I}$ falls). In this case, total welfare decreases as a result of an unprofitable merger. For $\eta$ to be negative after the merger, it has to be sufficiently negative before the merger, i.e., $\sum_{i \in O} \lambda_{i} x_{i}<<X_{I}$. The other possibility is that $\eta$ changes its sign in the course of the "infinitesimal mergers", but the total external effect is negative. Both reflect the point that "big mergers" should be addressed with caution.

Converting $\eta$ into market shares, this means that the insiders' market shares before the merger must be sufficiently large. In Fig. 1, this case is positioned in the southwestern quadrant $\delta$.

If the total external effect of an unprofitable merger is positive, two possibilities must be considered:

A. the negative change in insiders' profits outweighs the positive external effect, which causes total welfare to fall (area $\varepsilon$ ), or

B. the positive external effect is larger than the negative change in insiders' profits, which causes total welfare to rise (area $\zeta$ ). 
In case $A$, the positive external effect must not be too large because the probability is increased that the profit change of the insiders will be outweighed. A sufficient condition for the external effect to be positive is given by $\eta \geq 0$ before the merger. First, the described situation is fulfilled the closer $\eta$ lies to zero before the merger. Second, $\eta$ changes its sign in the course of the "infinitesimal mergers", and the total effect is larger than zero. In both cases, the result is a fall in total welfare because the negative change in insiders' output amounts to more than the positive external effect. Both mentioned cases again address caution toward permission for "bigger mergers".

In case $\mathrm{B}$, the positive external effect outweighs the change in insiders' profits. Despite the unprofitability of the merger, total welfare rises. Therefore, the total external effect must be sufficiently large. Due to the relationship between $\eta$ and $X_{I}$, this means that $\eta$ must be sufficiently large. The situation is most easily fulfilled if $\eta$ is positive, both before and after the merger, i.e., the difference between the weighted market shares of the outsiders and the insiders' market shares is positive before the merger and rises after it. Given that $\eta$ is positive both before and after the merger, this situation describes one possibility for the total external effect being large enough. Another possibility is that $\eta$ changes sign, and the functional relation $\eta(X)$ is strong enough so that the total effect can outweigh the negative change in insiders' profits. This describes situations that are supported by sufficiently low market shares of the insiders (note that the reaction parameters $\lambda$ of the outsiders would have to be considered as well; however, this complicates the analysis without altering the basic thought) and somewhat supports a cautious approach toward so-called "safe harbor" provisions.

\section{Consequences for Merger Policy}

Farrell and Shapiro (1990) draw their policy conclusions under the restrictive assumptions that only privately profitable mergers are proposed to the competition authorities. This implies that they (almost) exclusively look at the upper half of figure one. In doing so, their recommendation for merger policy reads: "Privately unprofitable mergers will not be proposed, so proposed mergers should be permitted unless their external effects are 'sufficiently' bad to outweigh their private profitability" (Farrell \& Shapiro, 1990, pp. 116-117).
The authors suggest a two-part procedure for merger review by competition authorities (Farrell \& Shapiro, 1990). First, determine the external effect $\left(\Delta W-\Delta \pi^{I}\right)$. If it is positive, allow the merger (area $\alpha$ ). If it is negative, then, second, estimate the profit effect $\left(\Delta \pi^{I}\right)$. If $\left|\Delta \pi^{I}\right|>\left|\Delta W-\Delta \pi^{I}\right|$, then allow the merger (efficiency defense; area $\beta$ ); otherwise, the merger should be prohibited (area $\gamma$ ).

Against the background of the empirics of mergers and acquisitions, however, the overall picture (according to section 3.3) must be interpreted to derive sound recommendations for competition authorities. Our interpretation of all six areas from the FSF (fig. 1), including the areas with unprofitable mergers (negative internal effect), reveals some concordance with Farrell and Shapiro but also some extensions and divergences.

Area $(\alpha): \Delta \pi^{I}>0 \wedge \Delta W-\Delta \pi^{I}>0$, both the internal and the external effect are positive. In compliance with Farrell and Shapiro, unconditional permission is recommended from a total-welfare perspective. Note, however, that employing a different welfare standard might alter the assessment. For instance, within EU competition policy, a consumer welfare standard is applied. While the total welfare standard seeks the maximization of the sum of producers' and consumers' rent, the consumer welfare standard seeks to maximize the consumers' rent. The FSF does not allow for straightforward conclusions regarding such a consumer welfare standard because the external effect $\left(\Delta W-\Delta \pi^{I}\right)$ comprises elements of producers' rents (the outsider firms to the merger) and the consumers' surplus: $\Delta W-\Delta \pi^{I}=\Delta \pi^{O}+C S$. Therefore, despite an overall positive external effect, consumers might be hurt, but their welfare loss is overcompensated by the increasing profits of the remaining competitors of the merging companies. The larger the external effect is, however, the less likely such a scenario becomes (if $\Delta W-\Delta \pi^{I}>>$, then $\Delta \pi^{O}>>>0$ to allow for $C S<0$ ). Vice versa, a negative external effect need not necessarily imply a reduction of consumer welfare because an increase in $C S$ might be overcompensated by a loss in $\Delta \pi^{O}$. Again, this becomes less likely with an increasingly negative external effect.

Area $(\beta): \Delta \pi^{I}>0$ and $\Delta W-\Delta \pi^{I}<0 \quad$ with $\left|\Delta \pi^{I}\right|>\left|\Delta W-\Delta \pi^{I}\right|$, i.e., the positive internal effect outweighs the negative external effect. This is the area in which an efficiency defense is meaningful and be- 
comes an important element of a welfare-maximizing merger policy. Despite anticompetitive effects (a reduction of the sum of consumers' rents and competitors' rents), total welfare is increased because the efficiency gains from the merger overcompensate them. Thus, permission is recommended from a total welfare perspective. Furthermore, even under a consumer welfare standard, some $\beta$-mergers might be approvable, namely, cases where the negative external effect results from a small increase in consumer welfare that is outweighed by a larger decrease in competitors' welfare. Therefore, prohibiting all $\beta$-mergers would be against welfare maximization even under a consumer welfare standard and, in some cases, protect competitors instead of consumers.

Area $(\gamma): \Delta \pi^{I}>0$ and $\Delta W-\Delta \pi^{I}<0 \quad$ with $\left|\Delta \pi^{I}\right|<\left|\Delta W-\Delta \pi^{I}\right|$, i.e., the negative external effect outweighs the positive internal effect. Mergers within this area are anticompetitive. Thus, prohibition is recommended from a total welfare perspective.

Area $(\delta): \Delta \pi^{I}<0 \wedge \Delta W-\Delta \pi^{I}<0$, both the internal and the external effect are negative. This area consists of anticompetitive mergers: thus, prohibition is recommended from a total welfare perspective. This area is neglected by the original FSF. Therefore, a merger policy abstaining from the frequent occurrence of unprofitable mergers might err here. The FSF implies an asymmetric treatment: while a positive external effect suffices to allow a merger, a negative external effect is not sufficient to prohibit a merger, simply because the internal effect is assumed to be positive and, therefore, a trade-off inevitably arises. Consequently, $\delta$-mergers would not be blocked automatically in the course of the two-part procedure suggested by Farrell and Shapiro (see above). Instead, their destiny would depend on the estimation of the internal effect that is - as Farrell and Shapiro (1990) admit - subject to some error risk. False positives (allowing a welfare-reducing merger) might, nevertheless, be rare because the competition authority should not find substantial efficiencies in such cases (that potentially outweigh the negative external effect) and thus should - in practice - prohibit these cases anyway. A residual might arise in cases where the negative external effect is very small, and the authority is thus willing to accept rather vague efficiencies because in a world without unprofitable mergers, almost every merger would be able to offset a small negative external effect. Then, false positives could occur to a certain extent if awareness of the frequent occurrence of privately unprofitable mergers is lacking.

Area $(\varepsilon): \Delta \pi^{I}<0$ and $\Delta W-\Delta \pi^{I}>0$ with $\left|\Delta \pi^{I}\right|>\left|\Delta W-\Delta \pi^{I}\right|$, i.e., the negative internal effect outweighs the positive external effect. In this case, a merger policy following the original FSF analysis commits errors, more specifically false positives. Due to the positive external effect, the merger is allowed although total welfare is reduced. In the modified interpretation, where unprofitable mergers are considered, $\varepsilon$-mergers are anticompetitive and should be prohibited under a total welfare standard. This leads to the important implication that the general recommendation of the original FSF - every merger with a positive external effect should be permitted - cannot be sustained in the modified FSF (inclusion of privately unprofitable mergers).

\section{Result I: If unprofitable mergers are allowed to be proposed, a positive external effect does not represent a sufficient condition for the allowance of a merger anymore!}

If a consumer welfare standard is considered, then the assessment of area $(\varepsilon)$ becomes more difficult because of the positive external effect. The latter comprises the effect on competitors and consumers, so there can be a case where consumer welfare is positive. Therefore, while Result I stands that a positive external effect is not a sufficient condition to clear a merger proposal, $\varepsilon$-mergers are not generally prohibited under a strict consumer welfare standard - in contrast to a total welfare standard.

Area ( $\zeta): \Delta \pi^{I}<0$ and $\Delta W-\Delta \pi^{I}>0 \quad$ with $\left|\Delta \pi^{I}\right|<\left|\Delta W-\Delta \pi^{I}\right|$, i.e., the positive external effect outweighs the negative internal effect. Although the original FSF does not expect $\zeta$-mergers to occur, a respectively styled merger policy would not make mistakes in such cases. Due to the positive external effect, $\zeta$-mergers would be allowed, and this unwittingly corresponds to the resulting increase in total welfare. In a way, the right result is achieved for the wrong reasons.

However, if total welfare should be maximized consequently according to this framework, then the allowance of actually proposed $\zeta$-mergers would not 
suffice. Instead, it would imply enforcing $\zeta$-mergers even against the wishes of the firms because it increases total welfare and is Kaldor-Hicks-superior (Farrell and Shapiro, 1990 preferred to Pareto-optimality). As well as allowing an anticompetitive merger for efficiency reasons (area $\beta$ ) by assessing and judging the private profitability of a merger project, a competition authority in the FSF maximizes welfare if it evaluates and judges the external effect of possible mergers (that are not proposed voluntarily by the companies) and instructs them to merge in case it finds them located in area $\zeta$. The same holds for privately profitable mergers that are not proposed due to the imperfections of the merger process and self-interested managers and advisers but that would increase total welfare ( $\alpha$ - and $\beta$-mergers). Alternatively, the competition authority could apply subsidies as an instrument to promote $\zeta$-mergers (Dragone et al., 2006; Fauli-Oller, 2002). The latter instrument might be viewed to be less controversial in regard to existing laws (private property rights) and related societal values (freedom of investment). However, from a strict welfare point of view, it is also less optimal because of the resulting burden on taxpayers.

Farrell and Shapiro (1990) explicitly reject compulsion or subsidies to implement $\zeta$-mergers because "both of which would be enormous changes from our antitrust policy". We find this reasoning, however, not very convincing. In their article, Farrell and Shapiro draw policy conclusions and recommend certain merger policies, which implies that they intend to change hitherto antitrust policy in the first place. This stands in accordance with the widely held view that competition economics-research should be guiding the designing and reforming of practical competition policy. Moreover, a theory addressing why gradual changes will be recommended but not 'enormous' changes (wherever the delineation lies) is not provided. Furthermore, it lies at the heart of the FSF that a competition authority should maximize welfare by evaluating, assessing and eventually judging concrete merger projects. It cannot be derived from the framework why the welfare maximization activities of the competition authority should be restricted to voluntarily proposed merger projects. This line of argument becomes strengthened if firms are assumed to also engage in unprofitable mergers.
Despite rejecting Farrell and Shapiro's reasoning against enforcing welfare-enhancing mergers against the wishes of the companies, we share their concerns about a merger policy that instructs or subsidizes mergers. However, we find their reasons insufficient because the FSF does not include any element that rules out such a policy. Actually, the FSF on its own is compatible with a merger policy where the competition authority organizes and determines the market structure (instead of the competitive process) against the background of comprehensive evaluations of possible mergers and their welfare effects (orchestrative merger policy). Although this may appear to be too radical, there are actually tendencies toward a moderate version of this line of reasoning (Dragone et al., 2006 and Fauli-Oller, 2002 represent considerable steps in this direction.). The European Commission, for instance, has increasingly taken a constructive stance toward resolving anticompetitive merger proposals (without prohibiting them). In extensive negotiations with the merging companies and their competitors, the Commission seeks to develop remedies that mold the market structure in a way to maximize (consumer) welfare. This includes re-organizing market shares by orchestrated divestitures from the merging companies to (policy) selected competitors to rebuild the pre-merger market situation (Budzinski \& Kuchinke, 2012). Thus, although the Commission 'only' intervenes when a merger is voluntarily proposed by the companies, in the course of the merger control procedure, remedies may be negotiated that include additional takeovers by (previous) outsiders of the mergers induced by the competition authority. The degree of active re-modeling of a market in the course of merger control has considerably increased and may represent a mild version of orchestrative merger policy.

However, before implementing FSF into merger control, additional assumptions must be relaxed and controlled for the subsequent effects. This includes ambitious assumptions about the knowledge of the competition authority and the measurability of the actual internal and external effects. Additionally, it touches on basic questions of the primacy of individual disposition about property rights (freedom of competition). Additionally, in a public choice view, the development toward a comprehensive 'merger control 
and instruction agency' would enhance the powers and resources of a competition authority as a bureaucracy, which could fuel the self-interested adoption of comparable reasoning.

\section{Result II: An isolated application of the modified FSF implies far-reaching and controversial intervention opportunities for merger control authorities.}

\section{Conclusion}

In this paper, we demonstrate that the popular FSF relies sensitively in its policy conclusions on the assumption that rational agents will only propose privately profitable mergers. If this assumption were held, a positive external effect of a proposed merger would represent a sufficient condition to allow the merger. However, the empirical picture on mergers and acquisitions reveals a significant share of unprofitable mergers, and economic theory, moreover, demonstrates that privately unprofitable mergers can be the result of rational action. Therefore, we extend the FSF by explicitly allowing unprofitable mergers to occur with some frequency. This exerts a considerable impact on merger policy conclusions: while several insights of the original FSF are corroborated (f.i., efficiency defense), a positive external effect does not represent a sufficient condition for the allowance of a merger any longer. Applying such a rule would cause a considerable amount of false positives. In addition, an isolated application of the modified FSF implies far-reaching and controversial intervention opportunities for merger control authorities.

\section{References}

Andrade, G., Mitchell, M. \& Stafford, E. (2001). New evidence and perspectives on mergers. Journal of Economic Perspectives, 15(2), 103-120.

Barros, P. P., \& Cabral, L. (1994). Merger policy in open economies. European Economic Review, 38 (5), 1041-1055.

Beigi, M., \& Budzinski, O. (2013). Reservations on the use of event studies to evaluate economic policy decisions. Intereconomics - Review of European Economic Policy, 48 (3), 174-179.

Brueckner, J. K, \& Spiller, P. T. (1991). Competition and mergers in airline networks. International Journal of Industrial Organization, 9 (3), 323-342.
Bruner, R. F. (1988). The use of excess cash and debt capacity as a motive for merger. Journal of Financial and Quantitative Analysis, 23 (2), 199-217.

Budzinski, O. (2003). Cognitive rules, institutions, and competition. Constitutional Political Economy, 14 (3), 215-235.

Budzinski, O., \& Kuchinke, B. A. (2012). Deal or no deal: consensual arrangements as an instrument of european competition policy? Review of Economics, 63 (3), 265-292.

Cheung, F. K. (1992). Two remarks on the equilibrium analysis of horizontal merger. Economics Letters, 40 (1), 119-123.

Dickerson, A. P., Gibson, H., \& Tsakalotos, E. (1997). The impact of acquisitions on company performance: Evidence from a large panel of UK firms. Oxford Economic Papers, 49 (3), 344-361.

Dragone, D., Lambertini, L., \& Mantovani, A. (2006). Horizontal mergers with scale economies (Working Paper No. 571). Dipartimento Scienze Economiche, Universita' di Bologna.

Farrell, J., \& Shapiro, C. (1990). Horizontal mergers: an equilibrium analysis. American Economic Review, 80 (1), 107-126.

Farrell, J., \& Shapiro, C. (1991). Horizontal Mergers: Reply. American Economic Review, 81 (4), 1007-1011.

Faulí-Oller, R. (2002). Mergers between Asymmetric Firms: Profitability and Welfare. Manchester School, 70 (1), 77-87.

Firth, M. (1980). Takeovers, shareholders returns and the theory of the firm. Quarterly Journal of Economics, 94 (2), 315-347.

Fridolfsson, S. O. and Stennek, J. (2005). Why mergers reduce profits and raise share-prices: a theory of preemptive mergers. Journal of the European Economic Association, 3 (5), 1083-1104.

Fridolfsson, S. O. (2007). Anti- versus pro-competitive mergers (Working Paper No. 694). Research Institute of Industrial Economics. Retrieved from http://www.ifn.se/Wfiles/wp/wp694.pdf

Gugler, K., Mueller, D. C., Yurtoglu, B., \& Zulehner, C. (2003). The effects of mergers: an international comparison. International Journal of Industrial Organization, 21 (5), 625-653.

Hennessy, D. A. (2000). Cournot oligopoly conditions under which any horizontal merger is profitable. Review of Industrial Organization, 17 (3), 277-284. 
Jensen, M. C. (1986). Agency cost of free cash flow, corporate finance, and takeovers. American Economic Review, 76 (2), 323-329.

Kahneman, D. (2003a). A psychological perspective on economics. American Economic Review, 93 (2), 162-168.

Kahneman, D. (2003b). Maps of bounded rationality: psychology for behavioral economics. American Economic Review, 93 (5), 1449-1475.

Kaplan, S. N., \& Weisbach, M. S. (1992). The success of acquisitions: evidence from divestitures. Journal of Finance, 47 (1), 107-138.

Levin, D. (1990). Horizontal mergers: the 50-percent benchmark. American Economic Review, 80 (5), 1238-1245.

Neven, D. J. (2006). Competition economics and antitrust in Europe. Economic Policy, 21 (48), 742-791.

Nilssen, T., \& Sørgard, L. (1998). Sequential horizontal mergers. European Economic Review, 42 (9), 16831702.

Novshek, W. (1985). On the existence of Cournot equilibrium. Review of Economic Studies, 52 (1), 85-98.

Pautler, P. A. (2003). Evidence on mergers and acquisitions. The Antitrust Bulletin, 48 (1), 119-221.

Rau, P. R., \& Vermaelen, T. (1998). Glamour, value and the post-acquisition performance of acquiring firms. Journal of Financial Economics, 49 (2), 223-253.

Ravenscraft, D. J., \& Scherer, F. M. (1987). Mergers, sell-offs, and economic efficiency, Washington, DC: Brookings Institution.

Roll, R. (1986). The hubris hypothesis of corporate takeovers. Journal of Business, 59 (2), 197-216.

Röller, L. H., Stennek, J., \& Verboven, F. (2006). Efficiency gains from mergers. In F. Ilzkovitz \& R. Meiklejohn (Eds.), European merger control: do we need an efficiency defence? (pp. 84-101). Cheltenham, UK: Edward Elgar.

Salant, S. W., Switzer, S., \& Reynolds, R. J. (1983). Losses from horizontal merger: the effects of an exogenous change in industry structure on CournotNash equilibrium. Quarterly Journal of Economics, 98 (2), 185-199.

Shleifer, A., \& Vishny, R. W. (1988). Value maximization and the acquisition process. Journal of Economic Perspectives, 2 (1), 7-20.
Spector, D. (2003). Horizontal mergers, entry, and efficiency defences. International Journal of Industrial Organization, 21 (10), 1591-1600.

Tichy, G. (2001). What do we know about success and failure of mergers? Journal of Industry, Competition and Trade, 1 (4), 347-394.

Trautwein, F. (1990). Merger motives and merger prescriptions. Strategic Management Journal, 11 (4), 283-295.

Verboven, F. (1995). Corporate restructuring in a collusive oligopoly. International Journal of Industrial Organization, 13 (3), 335-354.

Werden, G. J. (1991). Horizontal mergers: comment. American Economic Review, 81 (4), 1002-1006.

\section{Acknowledgements}

We thank all of the participants of the 29th HOS

Conference (Marburg, November 2007), the 35th EARIE

Conference (Toulouse, September 2008) and the Annual Meeting of the Verein für Socialpolitik (Graz, September 2008) for valuable and helpful discussion of earlier versions of this paper. Furthermore, we thank Barbara Güldenring for editorial assistance. 


\section{Appendix}

We regard a simple model that is able to describe all possible types of mergers out of the graphical illustration in Figure 1 by referring to the analysis of Salant, Switzer and Reynolds (1983) in conjunction with Dragone et al. (2006).

Salant et al. (1983) regard the impact of mergers by referring to Cournot's classic example. Given the notation of section 3 of our paper, the inverse demand is given by $p(X)=\beta-X$, with $\beta>0, X$ denoting total industry output and $p$ denoting the price. The number of firms is exogenous and given by $n$. Firm $i$ 's output is given by $x_{i}$. It is assumed that the $n$ firms are identical with the same marginal costs $c$ and fixed costs $F$. Thus, total industry output is given by $X=\sum_{i=1}^{n} x_{i}$, and $\sum_{j \neq i} x_{j}=X-x_{i}$ summarizes the aggregated output of all firms other than firm $i$.

Firm $i$ now maximizes its profit by setting $x_{i}$, i.e., $\max _{x_{i}}[p(X)-c] x_{i}-F$. Assuming that the $n$ firms are identical, the output of each firm will be the same in a symmetric Nash equilibrium, i.e., $x_{i}=x_{j}=x$ (Salant et al., 1983), which is given by $x=(\beta-c) /(n+1)$. Price and profit of each firm will, therefore, be given by $p(X)=(\beta+n c) /(n+1)$ and $\pi(x)=[(\beta-c) /(n+1)]^{2}-F$, respectively.

Now, $m+1$ firms merge ("insiders"), and the number of independent firms decreases to $n-m$ ( $n=m$ describes the limiting case of the monopolization of a market). Thereby, $m$ can be interpreted as the size of the merger, i.e., the market share of the merging firms (Dragone et al., 2006; Salant et al., 1983). Different from the assumption of Salant et al. (1983) the merging firms do not totally shut down all of the plants but one. At this point, we rather refer to the analysis of Dragone et al. (2006). They assume that efficiency gains are "the outcome of an adjustment in fixed costs via the merger" (Dragone et al., 2006). The reduction in total fixed costs of the insiders following the merger amounts to a fraction smaller than $m F$ because of a "restructuration of production plants within the resulting firm" (Dragone et al., 2006); the fixed costs of the resulting firm amount to $(1+e) F$ with $e \in(0, m-1)$. The parameter $e$ thus describes the inefficiency of the merger, i.e., a higher value of $e$ is equal to lower restructuration gains. Marginal costs are unchanged.

Industry output and price are now given by $\hat{X}=\sum_{i=1}^{n-m} \hat{x}_{i}$ and $p(\hat{X})=\beta-\hat{X}$, respectively, whereas the roof denotes the post-merger situation. Each firm's output in the new symmetric Nash equilibrium is given by $\hat{x}=(\beta-c) /(n-m+1)$. The resulting price $p(\hat{X})=[\beta+(n-m) c] /(n-m+1)$ is larger than $p(X)$ for $\beta>c$, which must be fulfilled to have a strictly positive industry output. Insiders' profits and the profits of the $n-m-1$ outsiders (non-merging firms) amount to $\pi^{I}(\hat{x})=[(\beta-c) /(n-m+1)]^{2}-(1+e) F$ and $\pi^{o}(\hat{x})=[(\beta-c) /(n-m+1)]^{2}-F$, respectively.

According to Salant et al. (1983), the profitability of a merger is given by the difference between the post-merger profit $\pi^{I}(\hat{x})$ and the sum of the pre-merger profits of the 2 insiders (The first derivative with respect to $m$ is given by $\left.\frac{\partial \Delta \pi^{l}}{\partial m}=2(\beta-c)^{2} /(n-m+1)^{3}-(\beta-c)^{2} /(n+1)^{2}+F\right):$

$\Delta \pi^{I}=\pi^{I}(\hat{x})-(m+1) \pi(x)=$

$=(\beta-c)^{2}\left\{(n-m+1)^{-2}-(m+1)(n+1)^{-2}\right\}+(m-e) F$.

Joint Profits of the outsiders and the consumer surplus (CS) change as follows:

$$
\begin{aligned}
& \Delta \pi^{o}=(n-m-1)\left[\pi^{o}(\hat{x})-\pi(x)\right]= \\
& =\frac{\left[m^{2}(m-3 n-1)+2 m\left(n^{2}-1\right)\right](\beta-c)^{2}}{(n+1)^{2}(n-m+1)^{2}} \text {, and }
\end{aligned}
$$

$\Delta C S=C S(\hat{X})-C S(X)=$

$=\frac{\left[m^{2}(2 n+1)-2 n m(n+1)\right](\beta-c)^{2}}{2(n-m+1)^{2}(n+1)^{2}}$, respectively.

This results in the determination of the external effect due to Farrell and Shapiro (1990), i.e., the sum of the consumer surplus and joint outsiders' profits $\left(\Delta C S+\Delta \pi^{\circ}\right)$ :

$$
\begin{aligned}
& \Delta C S+\Delta \pi^{o}= \\
& =\frac{\left[m^{2}(2 m-1)-4 m-2 n m(1+2 m-n)\right](\beta-c)^{2}}{2(n-m+1)^{2}(n+1)^{2}} .
\end{aligned}
$$

The change in total welfare due to a merger is thus given by:

$$
\begin{aligned}
& \Delta W=\Delta \pi^{I}+\Delta \pi^{o}+\Delta C S= \\
& =(\beta-c)^{2}\left\{\frac{n-m}{n-m+1}-\frac{n}{n+1}-\frac{1}{2}\left(\frac{n-m}{n-m+1}\right)^{2}+\frac{1}{2}\left(\frac{n}{n+1}\right)^{2}\right\}+ \\
& +(m-e) F .
\end{aligned}
$$


We can now describe the effect of a merger in settings that differ in the crucial parameters $m, e$ and $F$. The first variation considers different sizes of mergers, the second variation considers the efficiency of restructuration due to mergers, and the third variation considers the possible amount of the second variation. Thereby, it is possible to describe all mergers out of the graphical illustration in Figure 1.

Generally, an increase in the inefficiency parameter $e$ reduces the profitability of the merger. Given the merger of two firms, or even a few, the variation moves along the areas $\alpha, \zeta$, and $\varepsilon$. Thus, the change in total welfare is more likely to be positive but small, and at some point, it drops below the $45^{\circ}$-line into the negative area. However, the change in the external effect does not turn out to be negative due to a positive development of the outsiders' profits. In contrast, if many firms merge, the change in the external effect does not turn out to be positive due to the highly negative impact on consumer surplus. Then, an increase in the inefficiency parameter $e$ also reduces the profitability of the merger, but the variation now moves along the areas $\beta, \gamma$, and $\delta$. Thus, an efficiency defense is more likely for high efficiencies; the change in total welfare quickly drops below the $45^{\circ}$-line into the negative area.

The number of merging firms also has a clear impact, which can be shown in a counter-clockwise move along the areas. The effects of a smaller number of firms can more often be illustrated by areas $\varepsilon, \zeta$, and $\alpha$, whereas the effects of a higher number of merging firms can more often be illustrated by areas $\beta, \gamma$, and $\delta$.

High fixed costs make the mergers more profitable, i.e., savings are possible in a higher amount. This result holds for a few as well as for many merging parties. Thereby, a higher inefficiency parameter $e$ increases the amount of fixed costs needed to turn a merger to be profitable. Given two merging parties, or even a few, increasing fixed costs lead to a variation along the areas $\varepsilon, \zeta$, and $\alpha$. Thus, the change in total welfare turns from negative into positive, and the change in the external effect does not turn out to be negative due to a positive development of the outsiders' profits. In contrast, if many firms merge, the change in the external effect does not turn out to be positive due to the highly negative impact on consumer surplus. Then, an increase in the fixed costs $F$ also increases the profitability of the merger, but the variation now moves along the areas $\delta, \gamma$, and $\beta$. Furthermore, small changes in the amount of fixed costs now also have very high impacts, and the resulting effects of a merger quickly switch between the mentioned areas.

Unprofitability of a merger is possible in this simple framework if many firms merge (i.e., a high market share of the merging firms) and/or if the inefficiency parameter is high (i.e., a merger is unlikely to lead to efficiencies). 